\title{
Equilibrium Model of Movable Elements of Micromechanical Devices with Internal Suspensions
}

\author{
Olga A. Ezhova1" ${ }^{*}$, Igor E. Lysenko ${ }^{2}$, Boris G. Konoplev ${ }^{3}$ and Filipp M. Bondarev ${ }^{4}$ \\ ${ }^{1}$ Southern Federal University, Institute of Nanotechnology, Electronics and Electronic Equipment \\ Engineering, Taganrog, Russian Federation; ezhova.08.05@gmail.com \\ ${ }^{2}$ Southern Federal University, Institute of Nanotechnology, Electronics and Electronic Equipment \\ Engineering, Taganrog, Russian Federation; ielysenko@sfedu.ru \\ ${ }^{3}$ Southern Federal University, Institute of Nanotechnology, Electronics and Electronic Equipment \\ Engineering, Taganrog, Russian Federation; kbg@sfedu.ru \\ ${ }^{4}$ Southern Federal University, Institute of Nanotechnology, Electronics and Electronic Equipment \\ Engineering, Taganrog, Russian Federation; dortt@mail.ru \\ * Correspondence: ezhova.08.05@gmail.com; \\ Academic Editor: name \\ Received: date; Accepted: date; Published: date
}

\begin{abstract}
In this work model of mirror elements equilibrium of the micromechanical components is developed, the behavior analysis of the mirror element of micromechanical mirrors in case changing of control voltages of electrostatic actuators is carried out, an expression for determining the maximum value of deflection voltage at which the snap-down effect will take the following form is obtained in case of the influence of the coefficient of the electrostatic rigidity of electrostatic actuators. The developed equilibrium model of mirror elements and the obtained results of modeling can be used at design of micromechanical mirrors with internal suspensions.
\end{abstract}

Keyword: micromechanical mirrors, equilibrium model, electrostatic actuators, criteria, coefficient.

\section{Introduction}

Optical systems have, over the past 50 years, revolutionized and now have a wide range of uses in telecommunications, information display and metrology. In the 1950's the invention of the laser allowed, for the first time, practical commercial and industrial applications of coherent optical systems. Everyday applications of optical systems are abundant, including optical systems that use light to translate electrical signals to visible images (video displays, laser printers), and optical systems that use light to translate from visible images to electrical signals (digital cameras, barcode scanners).Optical systems are although quite useful for many applications, but the devices based on the optical systems have limits of performance because of their components overall dimensions. For example conventional mechanical scanners have significant performance limitations due to their scanning mirrors size. Miniaturization of optical components has enabled many of applications $[1,3]$.

Microelectromechanical systems (MEMS) technology - a set of manufacturing techniques broadly based on semiconductor manufacturing processes - is widespread in the world. The range of areas in which MEMS-devices are demanded promptly extends thanks to small overall dimensions, high-speed performance and rather low price. MEMS promises to bring the benefits of miniaturization to mechanical optical elements: low-cost, reliable opto-mechanical components. MEMS technologies have made micron- to millimeter-sized mechanical systems. MEMS sensors have been widely available for a various applications, including different kinds of sensors. MEMS actuators are widely used in inkjet printers. The application of these MEMS manufacturing techniques create a revolution in opto-mechanical systems [1-3]. 
Microopticoelectromechanical systems(MOEMS) is one of popular promising direction of optical systems development The basic concept of MOEMS is the miniaturization of combined optical, mechanical, and electronic functions into an integrated assembly, or monolithically integrated substrate, through the use of MEMS techniques. MOEMS is a rapidly growing area of research and commercial development with great potential to impact daily life. MOEMS-devices can be applied to optical scanning - both resonant beam scanning and steady-state beam steering and will ultimately result in all of the performance gains, such as to reduce size and cost, increase speed, and reliability, and accuracy. One of the most important MOEMS-components in fabrication of scanner are scanning mirrors [1-3,5].

Electromechanical development and research of micromechanical mirrors is one of the directions of microopticoelectromechanical systems development. Micromechanical mirrors provides an overview of the performance enhancements that will be realized by miniaturizing scanning mirrors like those used for laser printers and barcode scanners, and the newly enabled applications, including raster-scanning projection video displays and compact, high-speed fiberoptic components. There are a wide variety of methods used to fabricate micromechanical mirrors each with its advantages and disadvantages. There are, however, performance criteria common to mirrors made from any of these fabrication processes. For example, optical resolution is related to the mirror aperture, the mirror flatness, and the scan angle. Micromechanical mirrors provides a framework for the design of micromirrors, and derives equations showing the fundamental limits for micromirror performance. These limits provide the micromirror designer tools with which to determine the acceptable mirror geometries, and to quickly and easily determine the range of possible mirror optical resolution [1-4].

The micromechanical mirrors are used commonly both in microsystems of optical streams management and in the laser and optical rangefinder. The rangefinders are used in orientation and navigation systems of mobile objects on a terrain relief [1,2].

In works [5,6] designs of integrated micromechanical mirrors with crosswise [7] and integrated internal suspensions [8-10] are considered.

\section{Problem statement}

Electrostatic actuators are applied to deviate a mirror element in the offered micromechanical components. All electrostatic actuators are featured by snap-down effect [9-15]. The criteria allowing to define a condition of occurrence of this effect can be obtained using the equilibrium model of the mirror element.

The developed model of mirror elements equilibrium of the micromechanical components can be shown in a normalized view:

$$
W(1-W \sqrt{n})^{2}=U^{*}
$$

where $W, n, \mathbb{D}^{*}$ are the dimensionless variables defined by equations:

$$
\begin{gathered}
W=\frac{l_{1}}{d} \operatorname{tg} \beta \\
n=\frac{l_{2}}{l_{1}} \\
U^{*}=\frac{\varepsilon \varepsilon_{0} w U_{\mathrm{OT}}^{2}}{{ }_{{ }_{\beta} \beta_{\text {max }} d} L}
\end{gathered}
$$

where $\varepsilon$ - relative dielectric permittivity of an air-gap; $\varepsilon_{0}-$ an electric constant; $\mathbb{R}_{1}, \mathbb{R}_{2}-$ distances from a rotation axis to edges of fixed electrodes of electrostatic actuators; $w$-width of fixed electrodes; $d$ - distance between fixed electrodes of electrostatic actuators and a mirror element; $\beta$, $\beta_{\max }$ - angle and the maximum error angle of a mirror element; $k_{\beta}$ - coefficient of rigidity of elastic suspension of mirror element; $U^{*}$ - deflection voltage; $L$ - length of a mirror element.

\section{Results and discussion}

Figure 1 shows the dependence of the relative shift of a mirror element $W$ on applying voltage 


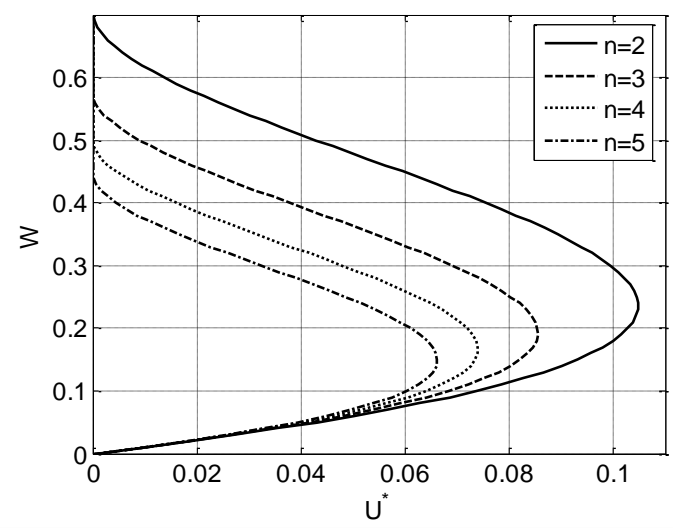

$\mathrm{U}^{*}$ when the relative size $\mathrm{n}$ fixed electrode of electrostatic actuators has different values.

Figure 1. Dependence of relative shift of a mirror element $W$ on the applied voltage of $U^{*}$

In Figure 1, the curves show the behavior of the mirror element of micromechanical mirrors in case changing of control voltages of electrostatic actuators. Optimal points of the curves define two system states: the low branch corresponds to the stable state of the system, and the top branch corresponds to the unstable state of the system. In an unstable state of the system slight change of control voltages leads to the snap-down effect and to the breakage of the device. Thus, the work of electrostatic actuators of micromechanical mirrors should run in the lower part of the curves. The location of the optimum is also affected by the configuration of electrostatic actuators, in particular, the size of stationary electrodes of electrostatic actuators.

Figure 2 and 3 show dependences of critical values of relative shift of the mirror element $W$ and the applying voltage defining the occurrence of snap-down effect on the relative size of fixed electrodes $n$.

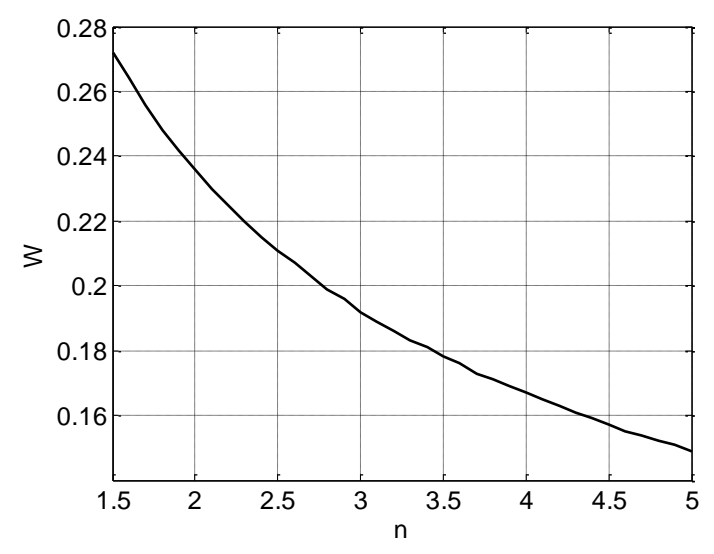

Figure 2. Dependence of relative shift of a mirror element $W$ on the relative size of fixed electrodes $\mathrm{n}$ of electrostatic actuator

Using the equations (1) - (4) and Figure 2, 3 it is possible to define the maximum value of deflection voltage leading to snap-down effect of a mirror element (for example, $n=2$ ): 


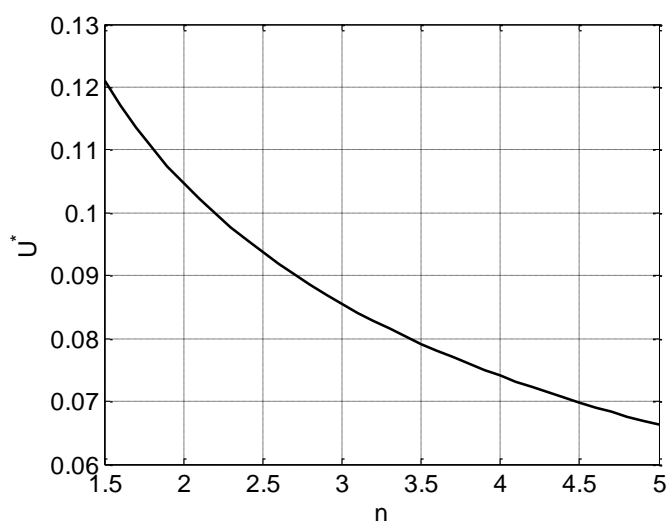

Figure 3. Dependence of the applying voltage lon the relative size of fixed electrodes $\mathrm{n}$ of electrostatic actuators

$$
\begin{gathered}
U_{\text {от1 }}=\sqrt{0,105 \frac{{ }^{k} \beta^{\beta_{\text {max }}}{ }^{d}}{\varepsilon \varepsilon_{0} w L}} \\
\tan \left(\beta_{\max }\right)=0,235 \frac{d}{l_{1}}
\end{gathered}
$$

However, equation (5) allows defining only the maximum value of constant deflection voltage $\mathrm{U}_{1}$.When applying of the deflection voltage changing according to defined harmonious law the maximum value leading to occurrence of snap-down effect will be more than $U_{1}$. This is due to the influence of the coefficient of the electrostatic rigidity is created by electrostatic actuators. In this case, an expression for determining the maximum value of deflection voltage at which the snapdown effect will take the following form:

$$
U_{\text {от2 }}=\sqrt{0,105 \frac{\left(k_{\beta}+k_{\text {эл }}\right) \beta_{\max } d}{\varepsilon \varepsilon_{0} w L}}
$$

\section{Conclusions}

The model of mirror elements equilibrium of the micromechanical components is developed, the behavior analysis of the mirror element of micromechanical mirrors in case changing of control voltages of electrostatic actuators is carried out, the dependence of the relative shift of a mirror element on applying voltage when the relative size $\mathrm{n}$ fixed electrode of electrostatic actuators has different values is showed, an expression for determining the maximum value of deflection voltage at which the snap-down effect will take the following form is obtained in case of the influence of the coefficient of the electrostatic rigidity of electrostatic actuators. The developed equilibrium model of mirror elements and the obtained results of modeling can be used at design of micromechanical mirrors with internal suspensions.

Acknowledgments: All This study was supported by the Ministry of education and science of Russia (project no. 213.01-11/2014-12) 


\section{References}

1. Berkeley S. sensor \& actuator center. Available online: http://www-bsac.eecs.berkeley.edu/ (accassed on 15.11. 2015 )

2. Konoplev, B.G.; Lysenko, I.E.; Ezhova, O.A.“Evolution criteria fingers hardness electrode MEMS comb converters", Bioscience. Biotechnology research Asia, India, vol.12,n.3, 2015

3. Zhou L., Optical MEMS for free-space communication, University of California, Berkeley, 2004

4. Konoplev B.G.; Lysenko, I.E. “Design of micromirror with electrostatic activation”, Journal of Microsystem Technique, Russia, vol. 12, pp. 22-25, Dec. 2002

5. Pristupchik, N.K.; Konoplev, B.G.; Kulikova, I.V.; Klunnikova, Y.V.; Lysenko, I.E.“Quantum Tunneling in Mesoscopic Electromechanical Transducers", Modern Applied Science, Canada, vol.9, no1,pp. 20-29, 2015.

6. Lysenko, I.E. "Modeling of integrated internal elastic suspension of a micromechanical device", Engineering journal of Don,vol.3. Available online: http://ivdon.ru/magazine/- Head from the screen/(accessed on 23.12.2014)

7. Lysenko, I.E. “Integrated micromechanical mirror”. Russian Federation. Patent 2265871 RF, Aug. 25, 2005

8. Konoplev, B.G.; Lysenko, I.E. “Integrated micromechanical mirror”. Russian Federation. Patent 2277255 RF, Aug.5, 2006

9. Raspopov, V. Ja. Micromechanical devices, Tula: Tula state university, 2007

10. Konoplev, B.G.; Lysenko, I.E.; Ezhova, O.A. "Criteria of equality of modal frequency of micromechanical gyroscopes- accelerometers sensitive elements", Modern Applied Science, Canada, vol.10, pp. 52-55, 2016

11. Lysenko, I.E. "Integrated sensors of angular velocities and linear accelerations" Engineering journal of Don,vol.3 [Online]. Available online: http://ivdon.ru/magazine/- Head from the screen/(accessed on 1.01.2016)

12. Konoplev, B.G.; Lysenko, I.E.; Ezhova, O.A. “Assessment criterion of rigidity of comb electrodes fingers of microelectromechanical converters", Modern Applied Science, Canada, vol.10, no2, pp. 52-55, 2016.

13. Lysenko, I.E.; Lysenko, A.V. “Integrated sensors of angular velocities and linear accelerations LR-type based on carbon nanotubes", Engineering journal of Don, 2010, vol.4 . Available online: http://ivdon.ru/magazine/- Head from the screen/(accessed on 10.12.2015)

14. Lysenko, I.E. "Modeling of biaxial micromechanical sensor of angular velocities and linear accelerations LR-type", Engineering journal of Don, 2013 , vol.1 Available online: http://ivdon.ru/magazine/- Head from the screen/(accessed on 15.01.2016)

15. Lysenko, I.E. "Modeling of the micromachined angular rate and linear acceleration sensors LL-type with redirect of drive and sense axis", World Applied Sciences Journal, Canada, vol.27,pp. 759-762, 2013

(C) 2016 by the authors; licensee Preprints, Basel, Switzerland. This article is an open access article distributed under the terms and conditions of the Creative Commons by Attribution (CC-BY) license (http://creativecommons.org/licenses/by/4.0/). 